\title{
Testing of Software for the Planning of a Linear Object GNSS Measurement Campaign under Simulated Conditions
}

\author{
Sławomir Figiel $^{1}$, Cezary Specht ${ }^{2}\left(\mathbb{D}\right.$, Marek Moszyński $^{1}$, Andrzej Stateczny ${ }^{3}{ }^{(1)}$ and Mariusz Specht ${ }^{4, *(D)}$ \\ 1 Department of Geoinformatics, Gdańsk University of Technology, Gabriela Narutowicza 11-12, \\ 80-233 Gdańsk, Poland; s179355@student.pg.edu.pl (S.F.); marmoszy@pg.edu.pl (M.M.) \\ 2 Department of Geodesy and Oceanography, Gdynia Maritime University, Morska 81-87, \\ 81-225 Gdynia, Poland; c.specht@wn.umg.edu.pl \\ 3 Department of Geodesy, Gdańsk University of Technology, Gabriela Narutowicza 11-12, \\ 80-233 Gdańsk, Poland; andrzej.stateczny@pg.edu.pl \\ 4 Department of Transport and Logistics, Gdynia Maritime University, Morska 81-87, 81-225 Gdynia, Poland \\ * Correspondence: m.specht@wn.umg.edu.pl
}

check for updates

Citation: Figiel, S.; Specht, C.; Moszyński, M.; Stateczny, A.; Specht, M. Testing of Software for the Planning of a Linear Object GNSS Measurement Campaign under Simulated Conditions. Energies 2021, 14, 7896. https://doi.org/10.3390/ en14237896

Academic Editors: Jae-Young Pyun and Alaelddin Fuad

Yousif Mohammed

Received: 1 October 2021

Accepted: 18 November 2021

Published: 25 November 2021

Publisher's Note: MDPI stays neutral with regard to jurisdictional claims in published maps and institutional affiliations.

Copyright: (c) 2021 by the authors. Licensee MDPI, Basel, Switzerland. This article is an open access article distributed under the terms and conditions of the Creative Commons Attribution (CC BY) license (https:// creativecommons.org/licenses/by/ $4.0 /)$.

\begin{abstract}
The precision of a linear object measurement using satellite techniques is determined by the number and the relative position of the visible satellites by the receiver. The status of the visible constellation is described by the Dilution Of Precision (DOP). The obtained geometric coefficient values are dependent on many variables. When determining these values, field obstacles at the receiver location and satellite positions changing with time must be taken into account. Carrying out a series of surveys as part of a linear object Global Navigation Satellite System (GNSS) measurement campaign requires the optimisation problem to be solved. The manner of the inspection vehicle's movement should be determined in such a way that the surveys are taken only within the pre-defined time frames and that the geometric coefficient values obtained at subsequent points of the route are as low as possible. The purpose of this article is to develop a software for the planning of a linear object GNSS measurement campaign to implemented in motion and taking into account the terrain model and its coverage. Additionally, it was determined how much the developed program improves DOP values on the planned route under simulated conditions. This software has no equivalent elsewhere in the world, as the current solutions for the planning of a GNSS measurement campaign, e.g., Trimble GNSS Planning, GNSS Mission Planning, or GPS Navigation Toolbox, allow the satellite constellation geometry to be analysed exclusively for specific coordinates and at a specific time. Analysis of the obtained simulation test results indicates that the campaign implementation in accordance with the pre-determined schedule significantly improves the quality of the recorded GNSS data. This is particularly noticeable when determining the position using the Global Positioning System (GPS) and GLObal NAvigation Satellite System (GLONASS) satellite constellations at the same time. During the tests conducted on the road along a three-kilometre-long route (tram loop) in Gdańsk Brzeźno, the average value of the obtained Position Dilution Of Precision (PDOP) decreased by $22.17 \%$ thanks to using the software to plan a linear object GNSS measurement campaign. The largest drop in the geometric coefficient values was noted for an area characterised by a very large number of field obstacles (trees with crowns and high buildings). Under these conditions, the PDOP value decreased by approx. $25 \%$. In areas characterised by a small number of field obstacles (single trees in the vicinity of the track, clusters of trees and buildings located along the track), the changes in the PDOP were slightly smaller and amounted to several percent.
\end{abstract}

Keywords: Global Navigation Satellite System (GNSS) mission planning software; linear object; Dilution Of Precision (DOP); satellite measurements

\section{Introduction}

Navigation is the process of controlling the movement of objects [1]. Its purpose is to determine the position coordinates of an object as a function of time, and to influence 
(control) the direction and velocity of its movement. The introduction of the earliest satellite positioning systems such as Transit (USA) or TSIKADA (USSR) to use in the middle of the 20th century initiated the era of satellite navigation that continues to this day. The Navigation Satellite System (NSS) is a general term encompassing Global Navigation Satellite Systems (GNSS) and Regional Navigation Satellite Systems (RNSS) which enable the positioning of receivers in space and the transmission of time signals. The systems that ensure global operating zone include the American NAVSTAR Global Positioning System (GPS), Russian GLObal NAvigation Satellite System (GLONASS), and the Chinese BeiDou Navigation Satellite System (BDS). The European satellite navigation system (Galileo) is currently under development and is likely to become fully operational soon. Navigation satellite systems with a regional operating zone include the Indian Regional Navigation Satellite System (IRNSS) which provides preliminary services and the Japanese QuasiZenith Satellite System (QZSS). The current status of the autonomous navigation system constellations is presented in Table 1 [2].

Table 1. The current status of the autonomous navigation system constellations (as of 26 August 2021).

\begin{tabular}{|c|c|c|c|c|c|c|c|}
\hline \multirow[b]{2}{*}{ Type of System } & \multicolumn{2}{|c|}{ Constellation Status } & \multicolumn{4}{|c|}{ Type of Orbit } & \multirow[b]{2}{*}{ Attentions } \\
\hline & $\begin{array}{c}\text { Current Number } \\
\text { of Satellites }\end{array}$ & $\begin{array}{l}\text { Number of Opera- } \\
\text { tional Satellites }\end{array}$ & MEO & GEO & GSO & IGSO & \\
\hline GPS & 34 & 30 & 34 & - & - & - & $\begin{array}{c}3 \mathrm{SV} \text { - in reserve } \\
1 \mathrm{SV} \text {-testing }\end{array}$ \\
\hline GLONASS & 26 & 23 & 26 & - & - & - & $\begin{array}{c}2 \mathrm{SVs} \text {-testing } \\
1 \mathrm{SV} \text {-in maintenance }\end{array}$ \\
\hline Galileo & 26 & 22 & 26 & - & - & - & $\begin{array}{l}3 \mathrm{SVs}-\text { not usable } \\
1 \mathrm{SV}-\text { not available }\end{array}$ \\
\hline BDS & 48 & 42 & 28 & 8 & - & 12 & $6 \mathrm{SVs}$-testing \\
\hline IRNSS & 8 & 7 & - & 3 & - & 5 & - \\
\hline QZSS & 4 & 4 & - & 1 & 3 & - & - \\
\hline Total satellites & 146 & 128 & 114 & 12 & 3 & 17 & - \\
\hline
\end{tabular}

It is reasonable to assume that, within the next few years, the number of navigation satellite systems all over the world will exceed 140 units, which will allow users to use them simultaneously, naturally within the available location. The summary provided in Table 1 does not take into account augmentation systems or the number of satellites still to be launched as part of supplementing them to obtain full constellations.

It follows from the presented analysis that multi-GNSS receivers are nowadays able to use over 140 satellites of different navigation satellite systems. It should be noted, however, that a single satellite is capable of transmitting several signals on multiple frequencies at the same time, which considerably increases the number of pseudorange measurements that can be used by the receiver. This is why multi-GNSS receivers are now widely used in car navigation systems, other mobile applications, smartphones and sports [3-8], as well as even including modern dual-frequency solutions [9-12]. Their very rapid development, associated with increasing the positioning accuracy, particularly in urbanised areas, results primarily from the rapidly increasing number of satellites of systems under construction [13-18].

The parameter informing about the spatial distribution of satellites in relation to the observer, on which the positioning accuracy using a NSS is dependent, is the Dilution Of Precision (DOP) which is the subject of this article [19-21]. Before discussing this parameter in detail, the factors affecting the positioning accuracy in GNSS systems will be presented. According to [22-25], the positioning accuracy is determined by the value of the selected DOP and the User Equivalent Range Error (UERE), which comprises the User Range 
Error (URE) and the User Equipment Error (UEE). In view of the above, the formula for positioning accuracy can be represented by the following relationship:

$$
D R M S=U E R E \cdot D O P=\sqrt{U R E^{2}+U E E^{2}} \cdot D O P,
$$

where:

DRMS-Distance Root Mean Square (m),

UERE-User Equivalent Range Error (m),

URE-User Range Error (m),

UEE-User Equipment Error (m),

$D O P$ - the appropriate geometric coefficient of the satellite location in relation to the receiver: Geometric Dilution Of Precision (GDOP), Position Dilution Of Precision (PDOP), Horizontal Dilution Of Precision (HDOP), Vertical Dilution Of Precision (VDOP), and Time Dilution Of Precision (TDOP) (-).

The above equation for the positioning accuracy in the GNSS system has a simplified form, which makes it sufficient and universal for multiple applications. It is correct since all the errors of the pseudorange measurement are subject to normal (Gaussian) distribution.

Based on relationship (1), it should be concluded that, at present, the main parameter whose value can be influenced by the system user is the DOP [26-29]. Its value is determined by the following: the instantaneous location of satellites in relation to the observer, i.e., to the azimuth and the elevation, the number of satellites used to determine the position coordinates, the min. elevation cut-off that is set in the user's receiver to prevent the multipath of satellite signals, the observer's coordinates, etc. [15,30-32].

Reducing the DOP value, i.e., increasing the positioning accuracy is possible through the planning of a GNSS measurement campaign to select the optimum time for test performance [33-35]. There are many free of charge and commercial programs for the planning of a GNSS measurement campaign:

- Trimble Planning-free, proprietary software from Trimble Inc. It is the most popular product in the field of GNSS planning. Currently distributed as a web application, previously available in a slightly more extensive form as a program for Windows. It enables the determination of DOP values for specific coordinates and at a specific time. The previous version allowed to set a height mask, the current one only enables you to enter the min. elevation cut-off. The application takes into account all GNSS constellations, it also allows the filtration of individual satellites. The simulation results are presented in a series of simple graphs. It is not possible to read the exact values of all of them;

- SKYPLOT DEM-software described in [36]. Not available for download on the Internet. It was supposed to be a console tool for simulating DOP values for specific coordinates and at a specific time. The authors showed in their work the influence of the number of GNSS constellations used and terrain fields on the DOP. They used the height model;

- SatNav Toolbox - paid toolkit for the MATLAB package. They allow reading orbit data of navigation systems. The graphs drawn by them enable a simple analysis of the state of GNSS constellations for specific coordinates and at a specific time;

- GeoPAL-software described on the website of the European Union Agency for the Space Programme (EUSPA) [37], which was the beneficiary of the grant. The project website no longer exists, and no other information is available about it. It was supposed to be a program for the planning of a GNSS measurement campaign dedicated to farmers and supporting crop efficiency. It made it possible to plan operations in an arable land when geometric coefficients have the best values.

In addition to the above-mentioned comprehensive solutions, smaller components and tools should be mentioned. These include high-quality libraries designed to work with navigation data, such as GAMIT, GPS Toolkit and RTKLIB. There is also software 
specialised in calculating and simulating the availability of satellite data (e.g., Bernese GNSS Software and MAAST).

They have similar functions, and require the user to enter the following input data [38]:

- Approximate ellipsoidal coordinates $(\mathrm{B}, \mathrm{L}, \mathrm{h})$ of the measurement location;

- The indication of the difference between the local time and the Universal Time Coordinated (UTC), related to the selection of the appropriate time zone;

- The determination of the min. elevation cut-off. It was assumed in the surveying that this parameter value should be $10-15^{\circ}$ depending on the type of field obstacles;

- The selection of the day and the time interval during which the measurements will be carried out;

- The determination, if required, of field obstacles that denote these parts of the celestial sphere that will be "obscured" by the surrounding objects. To this end, field obstacles are entered manually into the software for planning GNSS measurements.

However, the current applications for the planning of a GNSS measurement campaign have many limitations that may result in the forecast measurement conditions being significantly different from the actual ones. Among other things, the available programs enable the determination of the effect of satellite constellation geometry on the positioning accuracy exclusively for a single measurement point. Therefore, they can only be used in surveying applications and should not be used for the planning of a linear object GNSS measurement campaign. Pursuant to [39], a linear object is a civil structure whose characteristic parameter is the length, in particular, a canal, a flood bank, a gas pipeline, a heat pipeline, a pipeline, a railway line, a road, a water supply, an overhead and underground (placed directly in the ground) cable line, cable ducting, as well as electric power line and traction. Another disadvantage of programs of this type is the approximate, and often inaccurate, determination of field obstacles found in the vicinity of the measurement location $[40,41]$. This can be particularly noticeable in urban, built-up areas which are referred to in the literature as urban canyons [41-43], where the tracking of each additional satellite has a significant effect on the positioning accuracy by the user [20,44]. It should also be noted that in urbanised areas, the multipath signal sent by the satellite to the user often occurs, which results in an increased position error [45-47]. Moreover, one must not forget the terrain model that is not taken into account in the applications for the planning of a GNSS measurement campaign. The authors believe that taking the Digital Surface Model (DSM) into account is an important factor when determining the satellite visibility, particularly those that are found at low topocentric elevations in relation to the observer.

Therefore, it was reasonable to develop a system for the planning of a linear object GNSS measurement campaign to be implemented in motion, taking into account the terrain model and its coverage. According to the authors, it can be successfully used in navigation applications, e.g., when carrying out an inventory of railway routes [48]. Moreover, it allows DOP values to be determined in a more realistic and reliable manner than the widely available programs.

The aim of this study is to test software for the planning of a linear object GNSS measurement campaign under simulated conditions. In order to achieve the main aim of the study, the following partial aims needed to be considered:

1. The determination of the schedule for the optimum navigation of a linear object, generated by the software for the planning of a GNSS measurement campaign;

2. A comparison of the PDOP obtained during the performance of simulation tests;

3. The assessment of the effect of field obstacles found along the linear object on the accuracy of GNSS measurement campaign planning.

This article is structured as follows: Section 2 describes the developed software for the planning of a linear object GNSS measurement campaign in terms of description, assumptions, requirements, user interface, input parameters, map, and results of the operation. Section 3 presents the method for conducting GNSS measurements (GPS and GPS/GLONASS) under simulated conditions, along with a demonstration of the obtained 
results. It then discusses how the designed program improves the accuracy of GNSS positioning on test sections, which differ in the number of field obstacles. The paper concludes with final (general) conclusions that summarise its content.

\section{Materials and Methods}

\subsection{Software Description}

The software is intended for supporting the process of carrying out satellite measurements of linear objects. It allows a GNSS measurement campaign to be planned at a time when the satellite positions around the inspection vehicle are optimal while taking into account the specificity of linear objects, including the fact that the surveys are carried out in motion and during a long time interval. The calculations take into account the effect of field obstacles on the satellite visibility. As a result of its operation, the program determines the schedule for the optimum navigation of a linear object. The inspection vehicle operator is informed about the locations at which the vehicle should stop in order to wait for the end of the unfavourable satellite constellation status and about the time when it should start again.

The software operation is not complicated. The user enters the time frame during which the campaign can be implemented, the parameters of the inspection vehicle's movement, the geometry of the test linear object, the current ephemeris data, and the elevation model of field obstacles. Once the calculations are made, the user obtains a schedule of the inspection vehicle's movement (the locations and times of stops and starts) that guarantees the globally optimal navigation constellation status during the GNSS measurement campaign. In addition, visualisations of the calculations made and the results obtained are also presented.

\subsection{Assumptions}

The analytical model used in the software generalises the GNSS measurement campaign planning process. It is not dedicated to any particular application. Since the model was designed to be as universal as possible, it is not dependent on the inspection vehicle type (e.g., a car, an aerial or surface vehicle, a pedestrian, or a rail vehicle) or on the linear object type (e.g., high-voltage lines, pipelines, or railway rails). The model is not linked to the measurement method applied or the instruments by which it is performed.

The software was developed based on a number of assumptions about the process of performing GNSS measurements which must be satisfied for the use of the program to be reliable:

1. A measurement of a single position is carried out instantaneously, which means that the duration of the performance is negligibly short in relation to the duration of travelling the consecutive route sections;

2. The test linear object is continuous (uninterrupted);

3. The inspection vehicle can stop at any point of the linear object;

4. The linear object is covered in one direction, without going back to the places already visited;

5. The vehicle moves in a uniform motion, at a constant velocity for the entire campaign, and is also capable of starting or stopping relatively instantaneously.

\subsection{Requirements}

The user must enter to the software the geometry of a linear object, created in external Geographic Information System (GIS) software (e.g., ArcGIS, Google Earth, and QGIS), ephemeris data in the Trimble Almanac format (optionally), and an elevation model of field obstacles in the form of the DSM in the GeoTIFF format.

Optionally, the software can use Internet access to download the base map and up-todate ephemeris data. 


\subsection{User Interface}

The main window of the software is divided into three areas (Figure 1). The panel on the left allows all analytical model parameters to be entered. The map area in the central part displays a base map with tiles derived from the OpenStreetMap project. Once the linear geometry has been loaded, its points are presented on the map to ensure that the user has loaded the correct data. Similarly, following the import of the DSM, the data area is presented as a rectangle on the map. The third area is used to present the effects of the model operation. Diagrams of the calculation results or the constellation status and the determined schedule are presented on separate tabs.

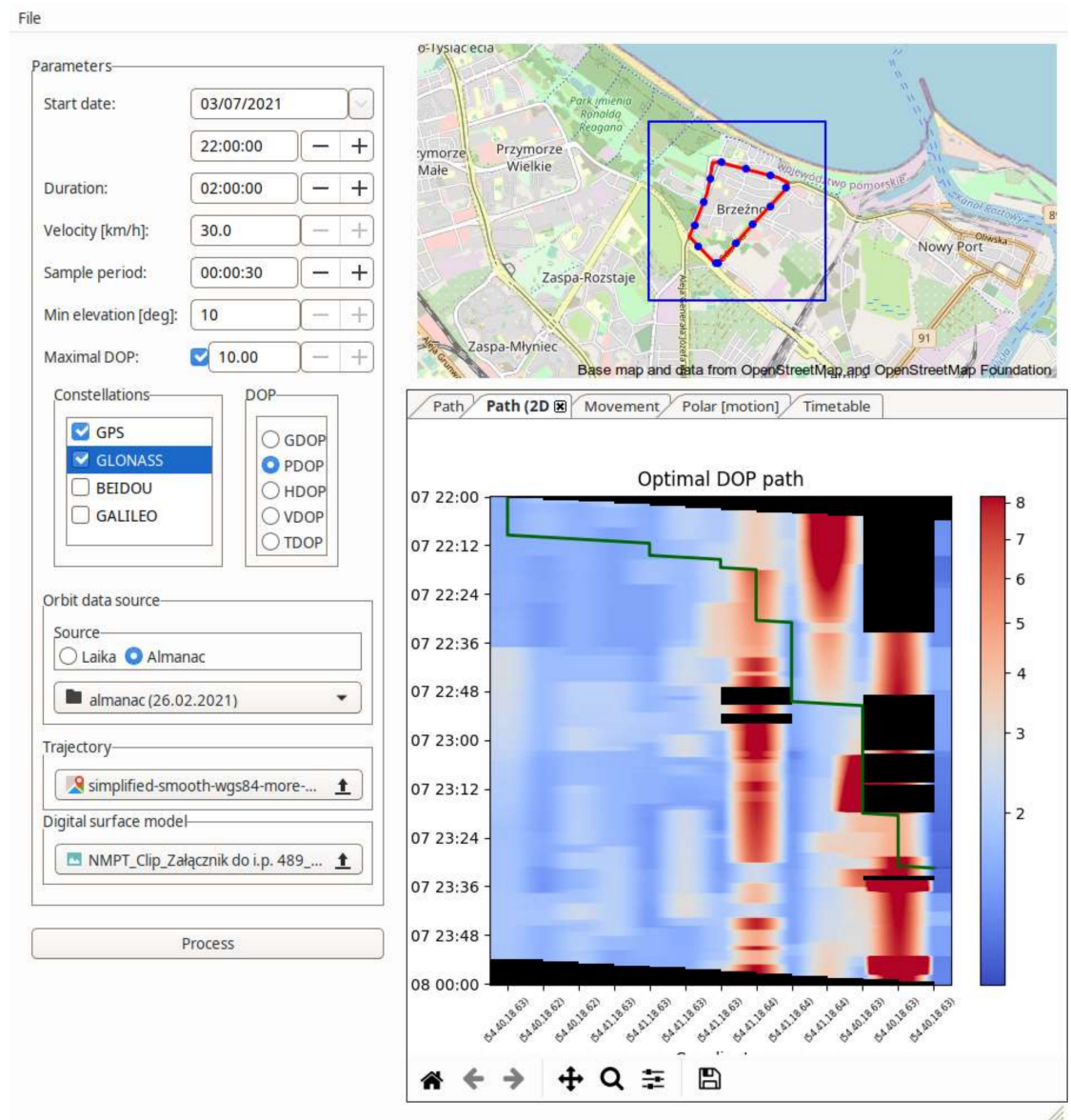

Figure 1. The main window of the software for the planning of a linear object GNSS measurement campaign.

\subsection{Input Parameters}

Input parameters are entered using the panel on the left side of the software window (Figure 2). 


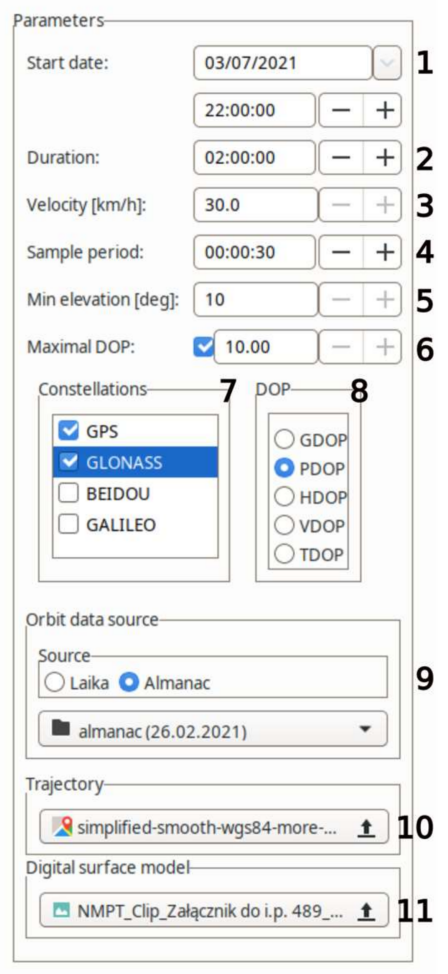

Figure 2. Input parameters of the software.

The "Start date" [1] sets the beginning of the campaign time frame. The planned campaign will not commence before this date.

The "Duration" [2] determines the max duration of the GNSS measurement campaign.

The "Velocity" [3] is the average velocity of the inspection vehicle in motion, expressed in kilometres per hour.

The "Sample period" [4] determines the time resolution of calculations made by the software. In combination with velocity, it also sets the spatial resolution of the analysis being carried out. The lower the value, the higher the quality of the schedule obtained. However, lowering the sample period value increases the duration of calculations dramatically. The value should be adjusted to the specificity of the inspection vehicle and its manoeuvring capabilities, as well as to the operating frequency of instruments.

The "Min. elevation" [5] limits from below the angular height of the satellite in relation to the inspection vehicle. The satellites visible at a lower angle will be regarded as if they are remaining below the horizon and will not be considered in calculations.

The "Maximal DOP" [6] determines the max value of the geometric coefficient that will be taken into account when mapping the optimal route. If the algorithm calculates that at a particular location and time that the DOP value obtained would be higher than that specified in this parameter, it will be assumed that the position at this point cannot be determined. Setting this value allows the "bottleneck effect" to be avoided. For certain points that are characterised by a great number of field obstacles, all satellites are only visible in narrow time windows. Usually, even then, the quality of positions obtained is not satisfactory. The algorithm, however, prefers to wait for such a window in order to obtain a finite (although extremely high) DOP value. This may lead to the degeneration of the optimal route. In order to avoid this problem, the parameter value being described should be set appropriately. The switch found next to the parameter value determines if it should be used. When selecting the value, the DOP assessment table can be used (Table 2) [49-51]. 
Table 2. Qualitative assessment of the satellite signal depending on the DOP value [49-51].

\begin{tabular}{|c|c|c|}
\hline DOP Value & Rating & Description \\
\hline$<1$ & Ideal & $\begin{array}{l}\text { At this value level, measurements can be carried out in } \\
\text { applications that require the highest possible precision at } \\
\text { all times. }\end{array}$ \\
\hline $1-2$ & Excellent & $\begin{array}{l}\text { The measurements are accurate enough to satisfy the } \\
\text { requirements imposed on the most critical applications. }\end{array}$ \\
\hline $2-5$ & Good & $\begin{array}{l}\text { This is the maximal DOP, for which accurate satellite } \\
\text { measurements of high reliability can be carried out. }\end{array}$ \\
\hline $5-10$ & Moderate & $\begin{array}{l}\text { Under these conditions, measurements using a NSS can be } \\
\text { carried out, but the positioning accuracy could be improved. A } \\
\text { more open view of the sky is recommended. }\end{array}$ \\
\hline $10-20$ & Fair & $\begin{array}{c}\text { With this satellite constellation geometry, measurements should } \\
\text { not be carried out using NSS systems, with the exception of } \\
\text { determining a very approximate position. }\end{array}$ \\
\hline$>20$ & Poor & $\begin{array}{l}\text { Under such conditions, measurements are inaccurate and } \\
\text { should not be carried out under any circumstances. }\end{array}$ \\
\hline
\end{tabular}

The "Constellations" [7] enable the selection of a set of GNSS systems used in the campaign planning. Four main global systems are available (GPS, GLONASS, BDS, and Galileo).

The "DOP" [8] area enables the selection of the geometric coefficient used during the planning. The DOP should correspond to the intended use of the measurement campaign. GDOP is the most general coefficient that estimates the constellation position quality simultaneously in the horizontal, vertical, and temporal dimensions. The equally often applied DOP is the PDOP, which assesses the distribution of constellations in a threedimensional space. For the determination of the DOP value exclusively on the horizontal plane, HDOP is used. Its equivalent on the vertical plane is the VDOP. The accuracy of determining the clock offset is specified by the TDOP. The determined schedule will differ depending on the coefficient used.

The "Orbit data source" [9] area includes two options. The first option, described as "Laika", enables the downloading of precise orbit data in the SP3 format directly from the National Aeronautics and Space Administration (NASA) servers (for the GPS constellation) or the Information and Analysis Center for Positioning, Navigation and Timing (IAC PNT) (for the other constellations). This method requires an Internet connection and can last for up to several min. It can also be temporarily unavailable due to maintenance works on the above-mentioned servers. The selection of the "Almanac" option enables the use of files in the Trimble Almanac format. The current file in this format is available on the Trimble website, which contains data on the satellites of all constellations.

The "Trajectory" [10] allows the linear object's geometry to be entered. After selecting the trajectory, it will be displayed in the map area.

The "Digital surface model" [11] allows the effect of field obstacles to be considered in the analysis. Although this is an optional field, it needs to be filled in order to obtain a correct schedule. The user should indicate the current (for the campaign time frame) DSM. After indicating the file, the data range will be marked on the map as a blue rectangle.

When all data have been entered, the user should click the "Process" [12] to start the calculations.

\subsection{Map}

The map area is found in the upper part of the software window (Figure 3). 


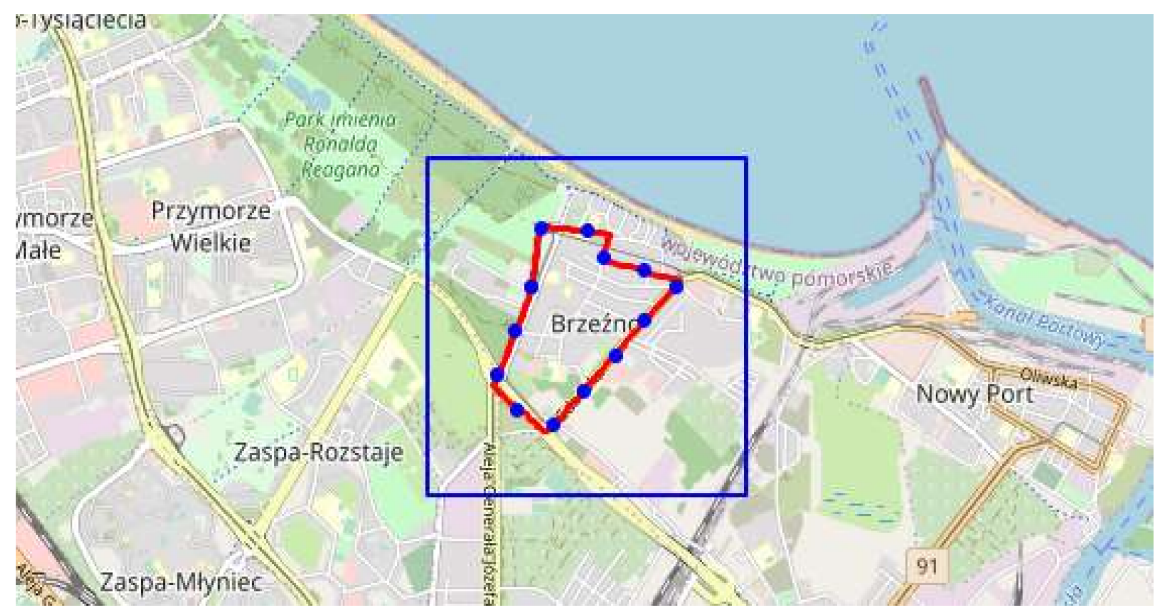

Figure 3. The software map area. The blue rectangle is the extent of the loaded DSM. The red line is an inspected route. The blue dots are sampling points where DOP values were calculated.

Internet access is required for the map to function correctly. The base map is downloaded on an ongoing basis from the OpenStreetMap project servers.

After adding the trajectory, it is drawn on the map as a red broken curve, and the map area is zoomed in to display it in its entirety. After the planning has been initiated, blue points are added to illustrate the locations for which the algorithm will make calculations of the constellation status and the satellite visibility.

After adding the DSM, a blue rectangle is drawn on the map with the selected data range, and the map area is zoomed in to display it in its entirety.

\subsection{Results of the Software Operation}

The results of the software operation appear in the lower part of the right-hand program column on the subsequent tabs. The software generates several tabs of diagrams illustrating the effect of the algorithm operation and one tab with the schedule.

\subsubsection{Diagram of the Optimal 3D Route}

The first tab is entitled "Path" and contains a three-dimensional diagram of the DOP value depending on the location and time (Figure 4). The "Time" axis contains the consecutive time moments of the campaign (the axis starts at the moment of the actual campaign commencement), and the "Coordinates" axis contains the consecutive points being part of the linear object. The value on the perpendicular "DOP" axis illustrates the geometric coefficient value at a particular location and time. The black line represents the optimal way of covering this space, from the initial point at the beginning of the linear object and the starting moment of time to the final point found at the last position of the linear object.

This diagram allows an understanding of how the software's algorithm operates. However, it can be inconvenient for analysing longer schedules. In this case, the graph on the next tab can be helpful. 


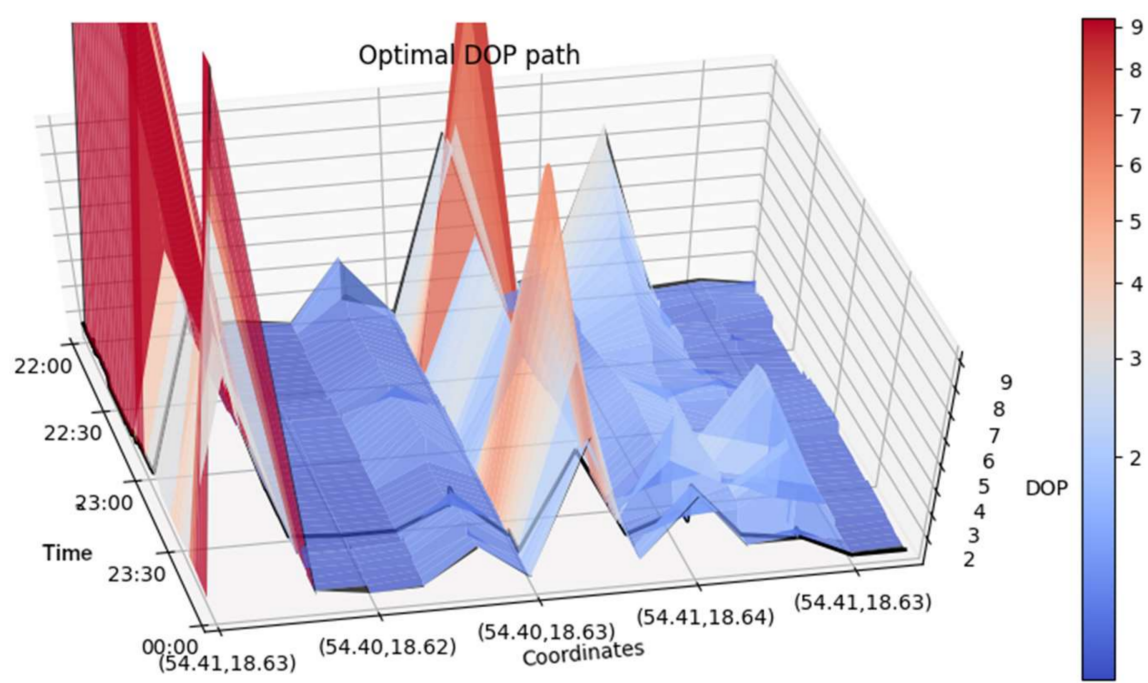

Figure 4. Diagram of the optimal 3D route. The surface presents DOP values for specific coordinates and at a specific time. The black line is an optimal route.

\subsubsection{Diagram of the Optimal 2D Route}

The second tab is entitled "Path (2D)" and contains the same information as the previous tab (Figure 5). The diagram, however, is two-dimensional and is a view from the top of the previous one. The optimal route is drawn as a green line. The black areas are locations for which the finite value of the DOP failed to be determined.

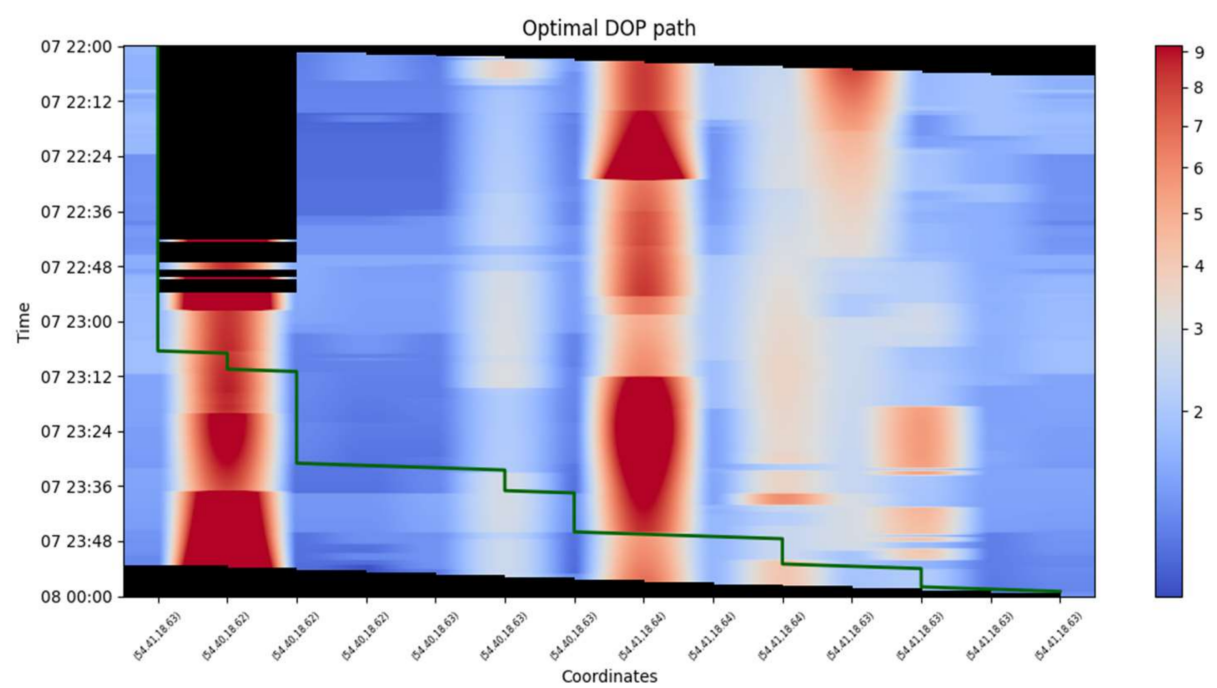

Figure 5. Diagram of the optimal 2D route. The colour of the surface depends on the DOP value. The black areas are locations for which the finite DOP value failed to be determined. The black triangles in the corners are unavailable areas. The green line is an optimal route.

\subsubsection{Diagram of Moving}

The third tab is entitled "Movement" and shows two diagrams (Figure 6). The graph on the left indicates the progress of the inspection vehicle's movement as a function of time. It illustrates the vehicle's movement and stopping in time. The right-hand area contains a diagram of the DOP value as a function of time over the inspection vehicle. It means that the geometric coefficient value at a particular time is determined for the vehicle position at a particular moment. On this graph, the diagram presented on the left side is also drawn in grey. 

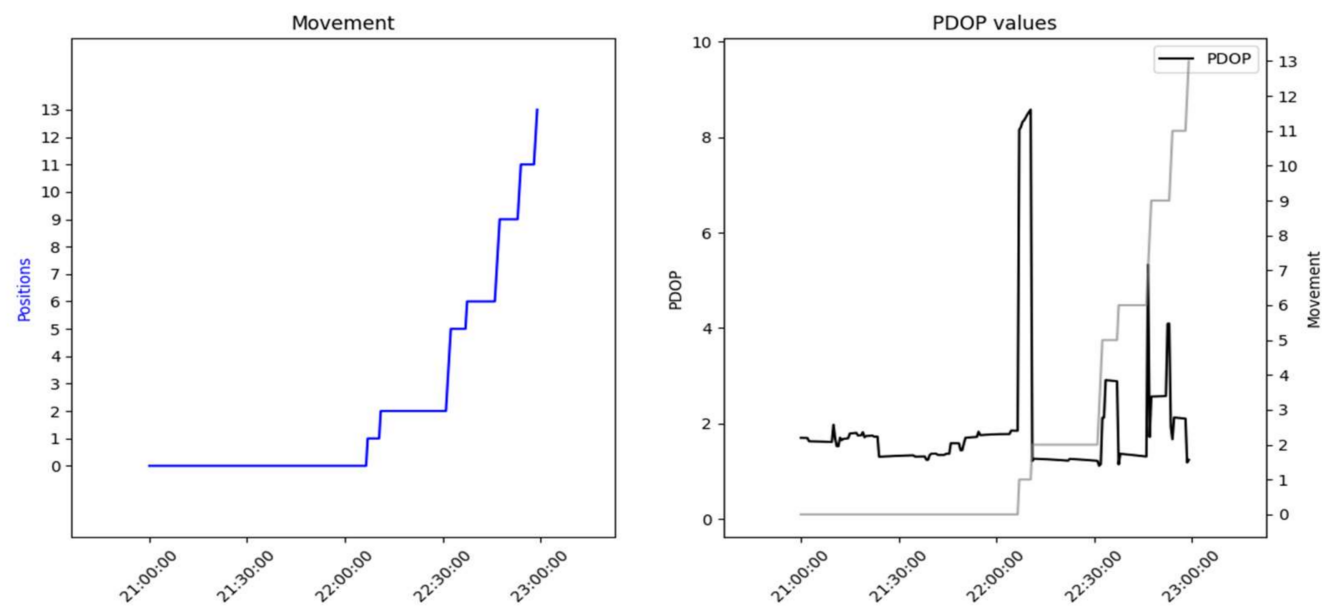

Figure 6. Diagram of moving. The left graph shows when the inspection vehicle is moving along the route. The right graph shows DOP values.

These diagrams enable the identification of the areas in which the inspection vehicle moves despite the high value of the DOP. This may be due to a large number of field obstacles or the "bottleneck effect". In case of a large number of such situations, consideration should be given to changing either the campaign time frame or its implementation method.

\subsubsection{Diagram of Satellite Movement}

The fourth tab entitled "Polar [motion]" shows the change in the satellite's location in the sky in relation to the inspection vehicle (Figure 7). The circular axis contains the satellite's azimuth value, while the axis located at the diagram's radius shows its topocentric elevation. Coloured lines are generated based on the satellite's positions during the campaign. The satellite identifier is found near the point at which the satellite was found at the beginning of the campaign. The graph ignores the discontinuities resulting from the satellite being obscured by field obstacles.

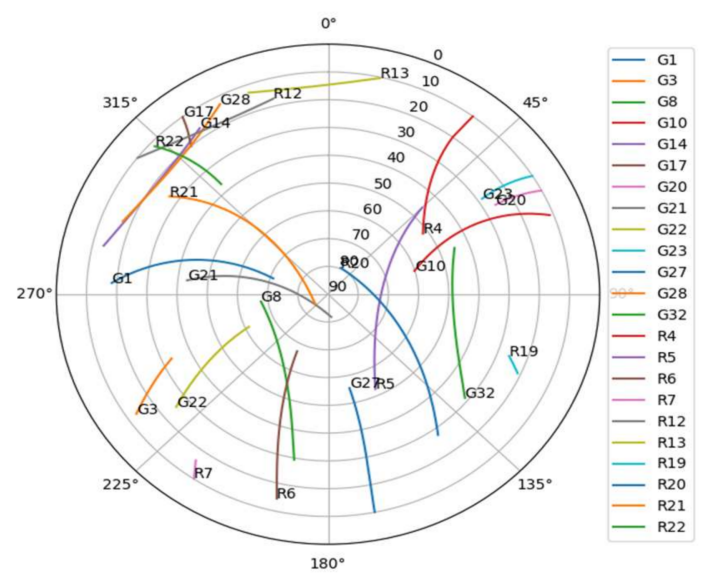

Figure 7. Diagram of satellite movement above the inspection vehicle on the optimal route. It is the azimuth and elevation plot. The satellite ID is located at the point where the satellite started to be visible.

The diagram can be used for the quality assessment of the constellation around the receiver and for the easy verification of the correctness of positions determined by comparing the results with the software modelling the satellite movement. 


\subsubsection{Movement Schedule}

The last tab, entitled "Timetable", is the proper result of the software operation (Figure 8). It is a table specifying the inspection vehicle's movement (starting and stopping) in such a manner that the quality of GNSS measurements during the campaign is at its highest.

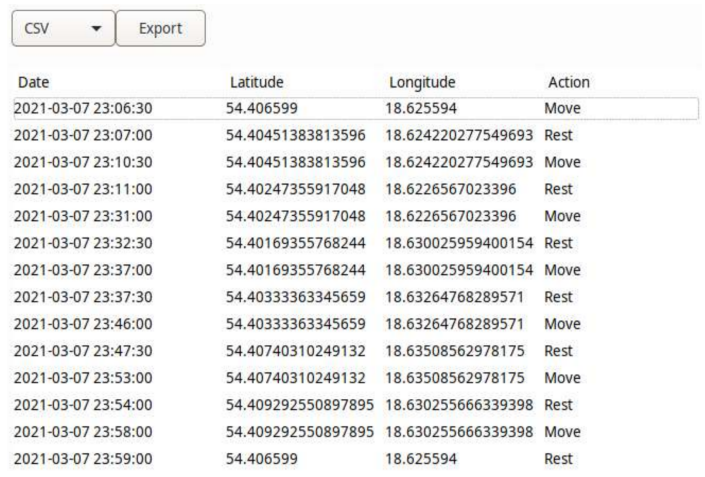

Figure 8. Movement schedule.

The software presents four columns. The first column specifies the manoeuvre performance date, the next two specify the coordinates of the manoeuvre performance location, and the last column specifies the action to be performed. The first line specifies the time and location (this is the first point of the linear object) of the beginning of the inspection vehicle's movement. The next two, in pairs, specify the location of the stop and the time of starting again. The last line indicates the moment when the campaign ends.

The schedule presented can be exported to a file in the CSV format. This file can be displayed in an Excel spreadsheet or imported to a GIS software and converted to files in GPX or KML formats used by navigation equipment. The data included in the file exported in this manner coincide with the data presented in the table. It is also possible to generate a file containing more detailed information. The resulting file will contain point sequences that make up the optimal method for the campaign implementation. The sequence contains all the points analysed by the program. The purpose of this export type is a further, advanced analysis using a GIS software.

\subsubsection{Computational Complexity}

The time complexity is:

$$
O(n)=S \cdot n \cdot \log n,
$$

where:

$S \sim \frac{w \cdot h}{d} \cdot S-$ complexity related to the external data: orbit and DSM (-),

$w$-DSM width (px),

$h$-DSM height (px),

$d$-DSM spatial resolution $(\mathrm{m} / \mathrm{px})$,

$s$ - the number of satellites from all chosen GNSS constellations (-),

$n=\frac{t}{p} \cdot \frac{l}{v \cdot p}$-the number of all available points for the inspection vehicle in terms of time and location $(-)$,

$t$-duration time (s),

$p$-sample period (s),

$l$-length of the route $(\mathrm{m})$,

$v$-velocity of the inspection vehicle $(\mathrm{m} / \mathrm{s})$.

The space complexity is:

$$
O(n)=n
$$




\subsubsection{Example of the Software Use}

This subsection presents an example of the software use for the first measurement campaign implemented on the road along a three-kilometre-long route (tram loop) in Gdańsk Brzeźno. In order for it to be implemented, the program user must perform the following operations:

1. Prepare the GeoJSON file in a GIS software, containing the planned route of the inspection vehicle;

2. Acquire the GeoTiFF file covering the campaign area;

3. Acquire the almanac file that is current as of 6 March 2021;

4. Enter the date of campaign commencement: 10:00:00 p.m. UTC+01:00, 6 March 2021;

5. Enter the campaign duration: 02:00:00;

6. Enter the velocity of the inspection vehicle: $30 \mathrm{~km} / \mathrm{h}$ (standard inspection velocity at which the mobile satellite measurements have been carried out to date);

7. Enter the sample period: $30 \mathrm{sec}$ (this parameter specifies the time resolution at which the calculations will be made by the software, and the possible minimal duration of the inspection vehicle's movement);

8. Enter the min. elevation: $10^{\circ}$;

9. Enter the max DOP: 10 (based on the publication by [49-51] these are the min. conditions under which GNSS measurements can be carried out);

10. Select all GNSS systems that are tracked by the navigation receiver. The use of all available global navigation satellite systems is crucial for achieving the highest efficiency;

11. Select the DOP: PDOP;

12. Select the Almanac ephemeris data source, and indicate the folder in which the file is found;

13. In the "Trajectory" field, indicate the file with the linear object's geometry created;

14. In the "Digital surface model" field, indicate the file with the DSM;

15. Click the "Process" button.

\section{Results}

\subsection{Measurement Location}

The tests will be carried out at night of the 6/7 March 2021, between 10:00:00 p.m. UTC+01:00 and 02:00:00 a.m. UTC+01:00, which will help avoid problems resulting from the movement of other vehicles. Mobile satellite measurements will be carried out on the road along a three-kilometre-long route (tram loop) in Gdańsk Brzeźno (Figure 9).

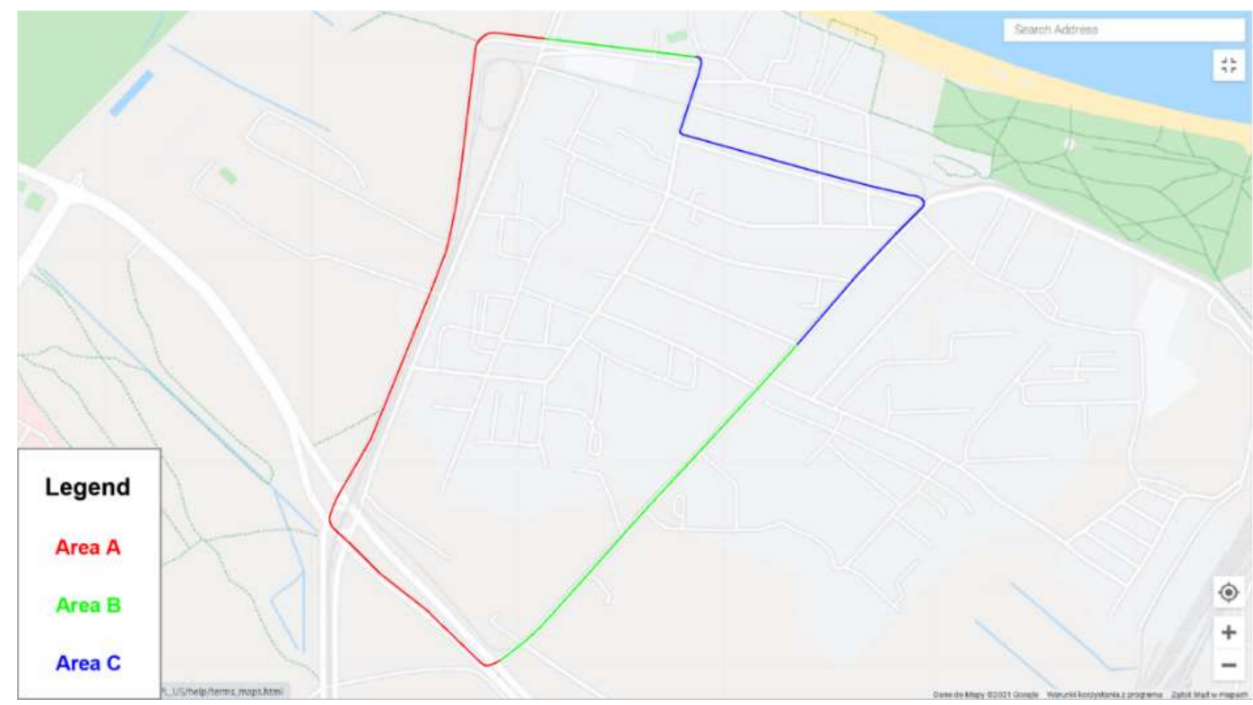

Figure 9. A plan of the test loop divided into different measurement areas. 
Area $\mathrm{A}$ is characterised by a small number of field obstacles (single trees in the vicinity of the track). However, area B is characterised by an average number of field obstacles (clusters of trees and buildings located along the track). On the other hand, area $C$ is characterised by a very large number of field obstacles (trees with crowns and high buildings). These zones were selected as the areas of research into the effect of field obstacles on the positioning accuracy.

\subsection{Measurements}

As part of the study, it is planned to carry out two measurement campaigns in the same way (the only difference between them will be the time of the campaign commencement).

\subsubsection{1st Measurement Campaign}

The measurements will commence at 10:00:00 p.m. UTC+1 on 6 March 2021, starting from point no. 1. Two inspection vehicles will cover the planned route with an average velocity of $30 \mathrm{~km} / \mathrm{h}$, without making any stops. The GNSS receiver on the first vehicle will record the position data (recording time, three-dimensional position coordinates, PDOP, etc.) with a frequency of $1 \mathrm{~Hz}$ using the GPS system. However, the GNSS receiver on the second vehicle will determine the position coordinates using the combination of GPS/GLONASS systems. Both inspection vehicles are expected to reach the final point of the route at approx. 10:06:30 p.m. UTC+1. It should be noted that none of the passages were planned using the software for the planning of a linear object GNSS measurement campaign.

Subsequently, it was decided to cover the planned route in a manner optimal in terms of the minimisation of the DOP value. To this end, the inspection vehicle's movement schedule generated by the test software was used. In order to be able to use it, the input parameters found in the panel on the left side of the program window had to be entered (Figure 10).
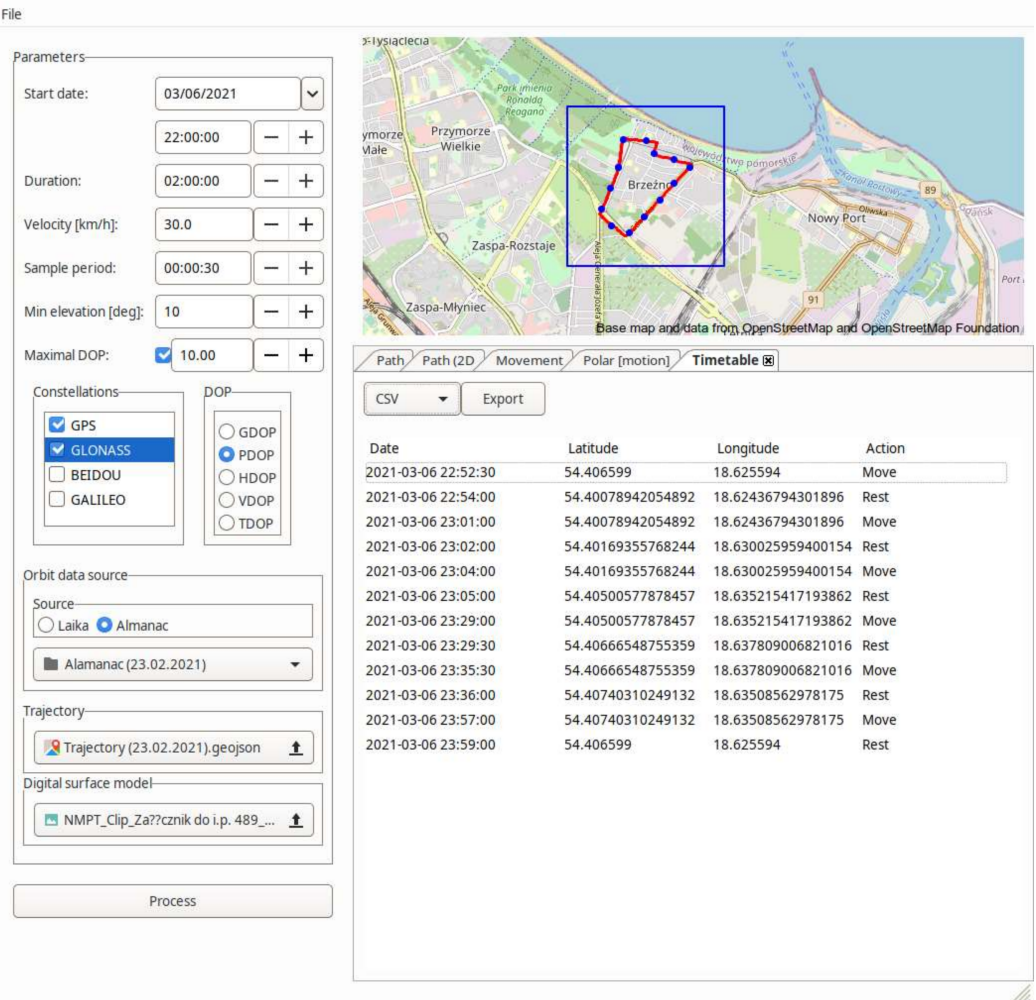

Figure 10. Window of the software for the planning of a linear object GNSS measurement campaign for the optimum variant during the performance of the first test series. 
For example, the simulation produced the optimal DOP path (Figure 11). It can be used to determine when and where the vehicle should start or stop along the planned route.

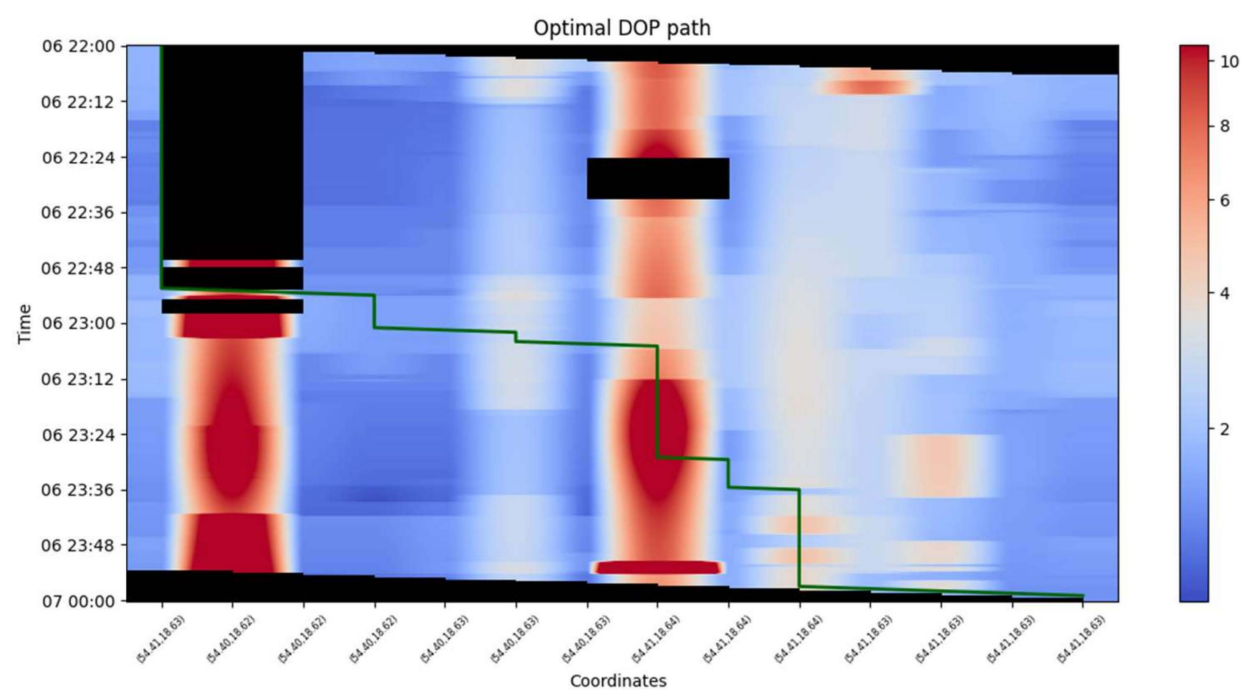

Figure 11. Diagram of the optimal 2D route during the first measurement campaign implementation.

Based on the results obtained, it was determined that the inspection vehicle will have to make five stops on the planned route. At 10:52:30 p.m. UTC+1, the vehicle will start from the initial point with a constant velocity of $30 \mathrm{~km} / \mathrm{h}$, and after $1.5 \mathrm{~min}$., it will stop at point no. 2. It will then wait at that point for 7 min., and at 11:01:00 p.m. UTC+1, it will start to move again along the planned route. The other stops at points no. 3, 4, and 5 will be made in an identical manner. At 11:59:00 p.m. UTC+1, the inspection vehicle will reach the place in which the tests were commenced.

\subsubsection{2nd Measurement Campaign}

The second measurement campaign was carried out almost identically to the first. The differences between them resulted from the time of the campaign commencement. The measurements will commence at 00:00 a.m. UTC +1 on 7 March 2021, starting from point no. 1. Two inspection vehicles started out from this point together and they moved with an average velocity of $30 \mathrm{~km} / \mathrm{h}$. They had reached the final point of the route at 00:06:30 a.m. $\mathrm{UTC}+1$. Subsequently, it was decided to cover the planned route in a manner optimal in terms of the minimisation of the DOP value (Figure 12).

For example, the simulation produced the optimal DOP path (Figure 13). It can be used to determine when and where the vehicle should start or stop along the planned route.

Based on the results obtained, it was determined that the inspection vehicle will have to make four stops on the planned route. At 00:58:00 a.m. UTC+1, the vehicle will start from the initial point with a constant velocity of $30 \mathrm{~km} / \mathrm{h}$, and after $2 \mathrm{~min}$., it will stop at point no. 2. It will then wait at that point for 2 min., and at 01:02:00 a.m. UTC+1, it will start to move again along the planned route. The other stops at points no. 3 and 4 will be made in an identical manner. At 01:50:00 a.m. UTC+1, the inspection vehicle will reach the place in which the tests were commenced. 

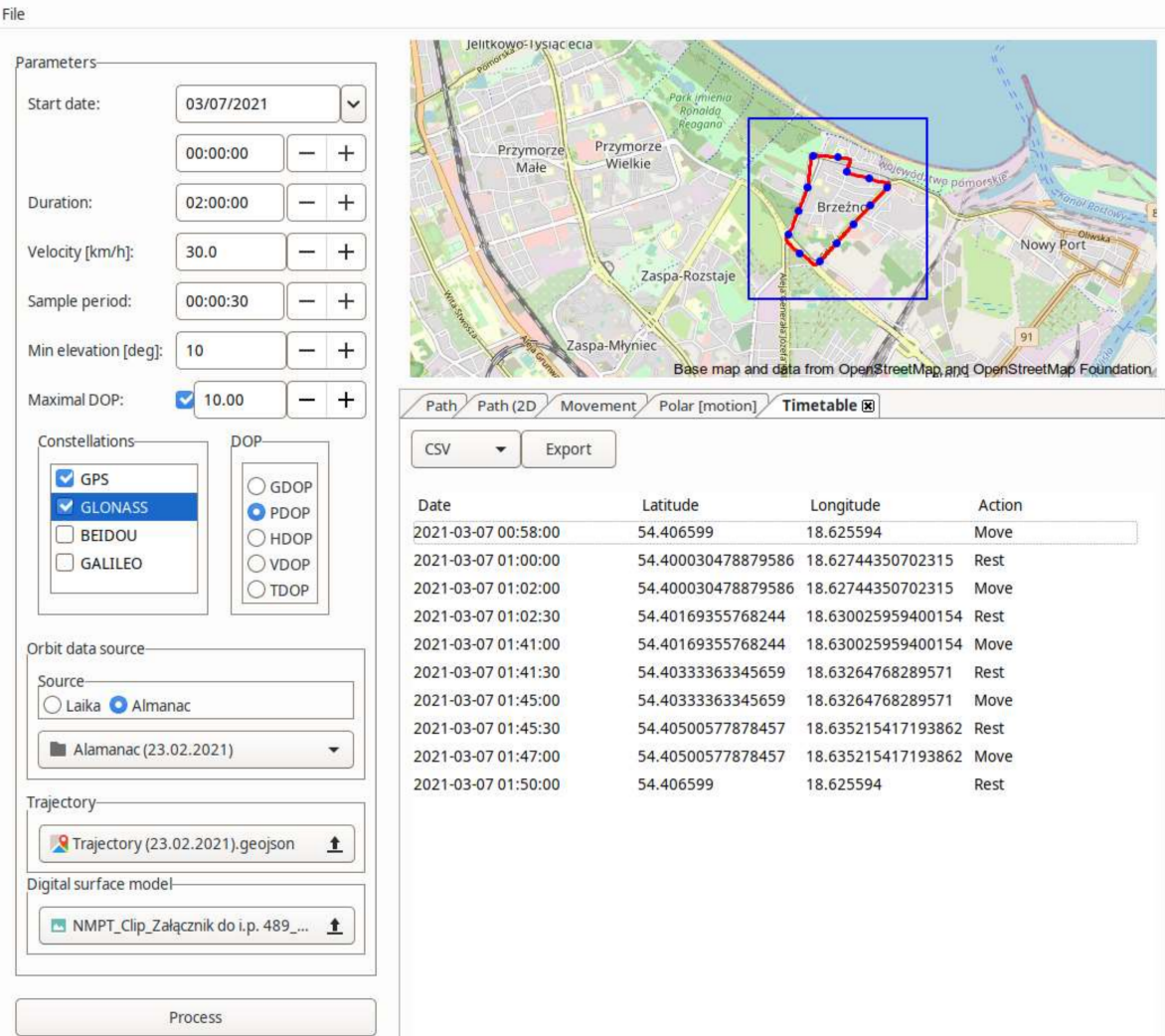

\begin{tabular}{|llll|}
\hline Date & Latitude & Longitude & Action \\
\hline 2021-03-07 00:58:00 & 54.406599 & 18.625594 & Move \\
\hline 2021-03-07 01:00:00 & 54.400030478879586 & 18.62744350702315 & Rest \\
2021-03-07 01:02:00 & 54.400030478879586 & 18.62744350702315 & Move \\
2021-03-07 01:02:30 & 54.40169355768244 & 18.630025959400154 & Rest \\
2021-03-07 01:41:00 & 54.40169355768244 & 18.630025959400154 & Move \\
2021-03-07 01:41:30 & 54.40333363345659 & 18.63264768289571 & Rest \\
2021-03-07 01:45:00 & 54.40333363345659 & 18.63264768289571 & Move \\
2021-03-07 01:45:30 & 54.40500577878457 & 18.635215417193862 & Rest \\
2021-03-07 01:47:00 & 54.40500577878457 & 18.635215417193862 & Move \\
2021-03-07 01:50:00 & 54.406599 & 18.625594 & Rest
\end{tabular}

2021-03-07 01:50:00

54.406599

18.625594

Figure 12. Window of the software for the planning of a linear object GNSS measurement campaign for the optimum variant during the performance of the second test series.

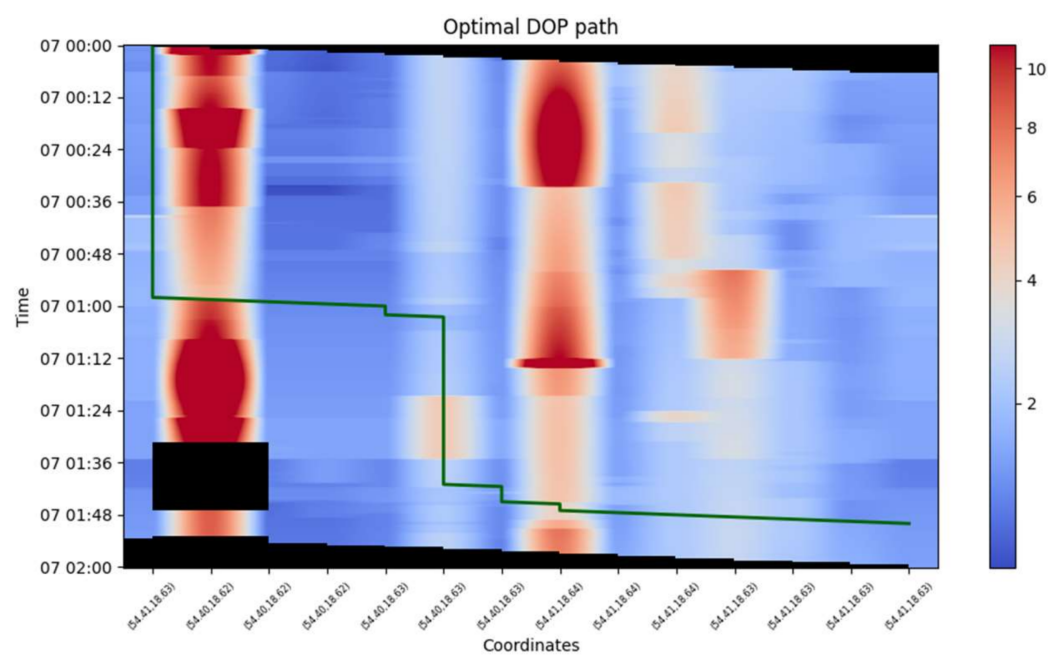

Figure 13. Diagram of the optimal 2D route during the second measurement campaign implementation.

\subsection{Analysis of Simulation Results}

The purpose of conducting the positioning measurements was to study a linear object. For this reason, it is important that the available samples are distributed evenly and as densely as possible. The following methodology appears to be appropriate. The trajectory is divided into small segments (a few or several metres in length). In each segment, a sample with a min. DOP value is selected, from which the average geometric coefficient value is calculated. The ratio of the segments containing any samples to all the segments is provided as well. The obtained average DOP value reflects the quality of the positioning 
measurements being carried out. The calculated ratio illustrates the availability of these surveys along the length of the linear object.

The software was configured to calculate the points that make up the optimal way to cover the planned route.

During the data processing, the points that are removed at the beginning include those at which the inspection vehicle did not move and those for which the DOP value was greater than the pre-defined max DOP value. The other points are subjected to the above-described segmentation to calculate the average DOP value and availability.

\subsection{Simulation Test Results}

The first (test) campaign will be aimed at the testing of software for the planning of a linear object GNSS measurement campaign under simulated conditions (Table 3). The second (verification) measurement campaign will be used to assess the reliability of the results obtained during the first test series (Table 4).

Table 3. The average values of the PDOP, obtained during simulation tests for the first measurement campaign.

\begin{tabular}{ccccccc}
\hline \multirow{2}{*}{ Area } & \multicolumn{2}{c}{ Continuous GPS Variant } & \multicolumn{2}{c}{ Continuous GPS/GLONASS Variant } & \multicolumn{2}{c}{ Optimal GPS/GLONASS Variant } \\
& Mean PDOP & Availability & Mean PDOP & Availability & Mean PDOP & Availability \\
\hline Entire route & 2.978 & $87.88 \%$ & 2.408 & $95.85 \%$ & 1.971 & $95.85 \%$ \\
Area A & 2.585 & $94.64 \%$ & 2.018 & $98.21 \%$ & 1.700 & $97.32 \%$ \\
Area B & 2.987 & $90.41 \%$ & 2.325 & $96.43 \%$ & 2.010 & $95.72 \%$ \\
Area C & 3.718 & $75.34 \%$ & 3.137 & $91.78 \%$ & 2.505 & $93.15 \%$ \\
\hline
\end{tabular}

Table 4. The average values of the PDOP, obtained during simulation tests for the second measurement campaign.

\begin{tabular}{ccccccc}
\hline \multirow{2}{*}{ Area } & \multicolumn{2}{c}{ Continuous GPS Variant } & \multicolumn{2}{c}{ Continuous GPS/GLONASS Variant } & \multicolumn{2}{c}{ Optimal GPS/GLONASS Variant } \\
& Mean PDOP & Availability & Mean PDOP & Availability & Mean PDOP & Availability \\
\hline Entire route & 2.768 & $89.81 \%$ & 2.065 & $96.60 \%$ & 1.989 & $96.70 \%$ \\
Area A & 2.212 & $97.32 \%$ & 1.636 & $99.11 \%$ & 1.741 & $99.11 \%$ \\
Area B & 2.781 & $92.41 \%$ & 1.949 & $97.77 \%$ & 1.885 & $95.24 \%$ \\
Area C & 3.837 & $76.71 \%$ & 2.891 & $91.78 \%$ & 2.500 & $95.89 \%$ \\
\hline
\end{tabular}

\section{Discussion}

In order to estimate the changes in the average PDOP value between individual positioning solutions for both measurement campaigns, it was proposed to adopt the relative percentage change in the average PDOP value, which is presented in Figures 14 and 15 based on the relationships [52]:

$$
\triangle P D O P_{G P S / G L O N A S S}=\frac{P D O P_{G P S / G L O N A S S_{c}, n, k}-P_{P D O P_{G P S / G L O N A S S}, n, k}}{P D O P_{G P S} / \text { GLONASS }_{0}, n, k} \cdot 100 \%,
$$

where:

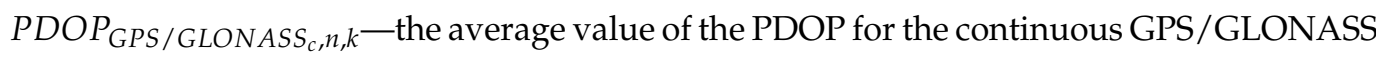
variant during the implementation of the $\mathrm{n}$-th measurement campaign on the $\mathrm{k}$-th route $(-)$, $P_{\text {DOP }}$ GPS/GLONASS $_{0}, n, k$ - the average value of the PDOP for the optimum GPS/GLONASS variant during the implementation of the $\mathrm{n}$-th measurement campaign on the $\mathrm{k}$-th route (-), $n$-measurement campaign number (-),

$k$-measurement route number $(-)$,

and:

$$
\triangle P D O P_{G P S-G P S / G L O N A S S}=\frac{P D O P_{G P S_{c}, n, k}-P D O P_{G P S} / G L O N A S S_{c}, n, k}{P D O P_{G P S} / G L O N A S S_{c}, n, k} \cdot 100 \%,
$$

where: 
$P D O P_{G P S_{c}, n, k}$-the average value of the PDOP for the continuous GPS variant during the implementation of the $\mathrm{n}$-th measurement campaign on the $\mathrm{k}$-th route $(-)$.

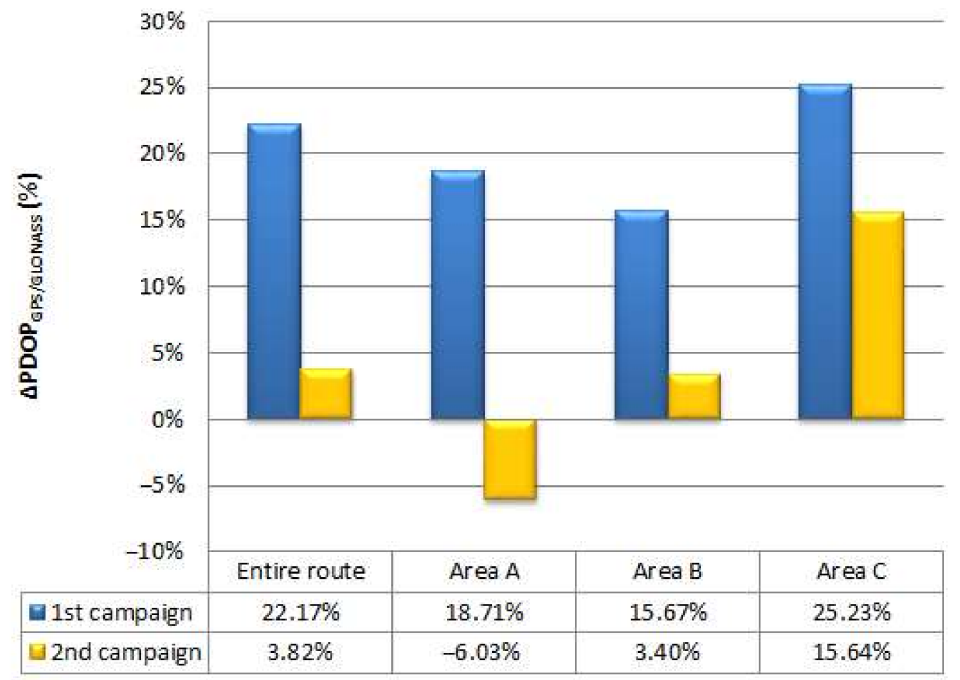

Figure 14. The relative percentage change in the average PDOP values between the continuous variant and the optimal variant for the GPS/GLONASS solution.

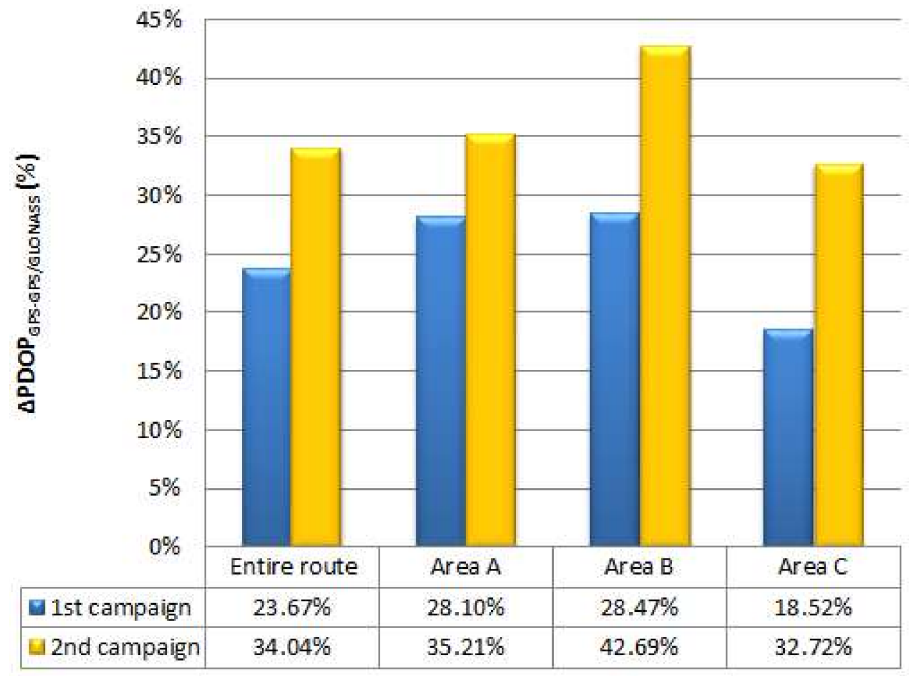

Figure 15. The relative percentage change in the average PDOP values between the continuous variant for the GPS and GPS/GLONASS solutions.

Analysis of the obtained simulation test results indicates that the campaign implementation in accordance with the pre-determined schedule significantly improves the quality of recorded GNSS data. This is particularly noticeable during the first measurement campaign. For example, the average PDOP value for the GPS/GLONASS solution decreased by $22.17 \%$ when software for the planning of a linear object GNSS measurement campaign was used (Figure 14). The greatest drop in the geometric coefficient was noted for area C, characterised by a very large number of field obstacles. In this case, the parameter value decreased by approx. $25 \%$. In areas A and B, which are characterised by a small number of field obstacles, the changes in the DOP value were slightly smaller and amounted to several percent. As regards the second measurement campaign, a slight decrease of $3.82 \%$ in the average PDOP value was noted. The changes in the geometric coefficient between the continuous and the optimal variant are minor, which undoubtedly results from the good geometry of satellite constellations during the implementation of the second measurement campaign in the continuous variant. Noteworthy is the fact that the average PDOP 
value, calculated in the optimal variant, does not always have to be lower than the average geometric coefficient value obtained in the continuous variant. It is noticeable for area $\mathrm{A}$ that the average PDOP value in the optimal variant is greater by approx. $6 \%$ than that in the continuous variant. As regards the availability of GNSS data, it is high during both measurement campaigns and ranges from 96 to $97 \%$. The highest positioning availability (approx. 99\%) was obtained in the area A. However, the lowest positioning availability (92-95\%) was noted for the area C.

In addition, it was decided to compare the average PDOP values obtained for the two commonly used positioning solutions, i.e., GPS and GPS/GLONASS. Based on Figure 15, it can be observed that the geometric coefficient values were definitely higher for the singlesystem solution than for the dual-system solution. The differences between them amounted to $23.67 \%$ for the first measurement campaign and $34.04 \%$ for the second measurement campaign. As regards the changes in the PDOP values in individual measurement areas (A, $B$ and $C)$, they were similar to each other. During the first measurement campaign, these changes ranged from 18.52 to $28.10 \%$, while during the second measurement campaign, they oscillated between 33 and 43\%. Therefore, it can be concluded that the average PDOP values in individual areas differ by only a few percent from the average geometric coefficient values calculated for all campaigns. Significant differences were observed for the positioning availability. For the GPS solution, this parameter ranged from 87.88 to $89.81 \%$, while for the GPS/GLONASS variant, it oscillated between 96 and 97\%. The greatest changes were noted for the area $C$, characterised by a very large number of field obstacles. In this case, the positioning availability fluctuated around $75 \%$, while for the GPS/GLONASS solution, it reached a value of almost $92 \%$.

\section{Conclusions}

The aim of this study was to develop software to enable the planning of GNSS measurements for a geodetic inventory of railway lines, roads, and other linear objects included in the terrain model. The resulting software was tested under simulated conditions. The experiments proved the high reliability of the model and confirmed the appropriateness of the measurement campaign planning.

Due to improvements in navigation systems, geodetic receivers, and reference station networks, access to precise position data is increasingly widespread. The rapid development of various economic sectors, e.g., high-speed rails, has paved the way for GNSS measurements to be used in new applications. Not only do modern land surveying products require the highest possible precision, but also the stability of surveys and their high availability. The use of satellite systems solves many traditional geodetic problems while introducing new complications. Carrying out measurements during an unfavourable constellation status can end in failure despite using state-of-the-art technologies. For this reason, it is important to plan a GNSS measurement campaign. The planning process must faithfully model the satellite constellation movements and field obstacles.

This publication raises an important and timely issue. Rapid technological development has raised the requirements imposed on geodetic products, which is noticeable in the field of the inspection of linear objects, including railway lines. The rising requirements for the precision and spatial resolution of data while reducing time windows for carrying out the measurements necessitates continuous improvements in the data acquisition process. The purpose of the issues addressed is to improve the quality of GNSS measurements by enabling the optimal use of the possibilities of satellite systems. In the future, planning may become a necessary step in every measurement campaign, and solutions such as the software presented will be indispensable tools in implementing this process.

In the next stage of the research, it is planned to test the software for the planning of a linear object GNSS measurement campaign under real conditions. The empirical tests will be carried out in the same way as in the simulation tests, i.e., GNSS receivers will be installed on two inspection vehicles, which will receive satellite signals in two variants: GPS and GPS/GLONASS. These vehicles will cover the planned route at a constant speed 
without any breaks. Subsequently, for the pre-defined time frames, both vehicles will cover the planned route in a manner optimal in terms of the minimisation of the DOP value.

Author Contributions: Conceptualisation, C.S. and M.M.; data curation, S.F., A.S. and M.S.; formal analysis, S.F., A.S. and M.S.; investigation, S.F., A.S. and M.S.; methodology, C.S. and M.M.; software, S.F.; supervision, C.S. and M.M.; validation, C.S. and M.M.; visualisation, S.F., A.S. and M.S.; writingoriginal draft, S.F. and M.S.; writing-review and editing, C.S., M.M. and A.S. All authors have read and agreed to the published version of the manuscript.

Funding: This research was funded from the statutory activities of Gdynia Maritime University, grant number WN/2021/PZ/05.

Institutional Review Board Statement: Not applicable.

Informed Consent Statement: Not applicable.

Data Availability Statement: Not applicable.

Conflicts of Interest: The authors declare no conflict of interest.

\section{References}

1. Specht, C. Radio Navigation Systems: Definitions and Classifications. J. Navig. 2021, 74, 945-954. [CrossRef]

2. Specht, C.; Specht, M. Navigation Users of Multi-GNSS Code Receivers. In Proceedings of the 19th International Multidisciplinary Scientific GeoConference (SGEM 2019), Albena, Bulgaria, 28 June-6 July 2019.

3. Engelbrecht, J.; Booysen, M.J.; van Rooyen, G.J.; Bruwer, F.J. Survey of Smartphone-based Sensing in Vehicles for Intelligent Transportation System Applications. IET Intell. Transp. Syst. 2015, 9, 924-935. [CrossRef]

4. Geng, J.; Jiang, E.; Li, G.; Xin, S.; Wei, N. An Improved Hatch Filter Algorithm towards Sub-meter Positioning Using only Android Raw GNSS Measurements without External Augmentation Corrections. Remote Sens. 2019, 11, 1679. [CrossRef]

5. Liu, W.; Shi, X.; Zhu, F.; Tao, X.; Wang, F. Quality Analysis of Multi-GNSS Raw Observations and a Velocity-aided Positioning Approach Based on Smartphones. Adv. Space Res. 2019, 5, 2358-2377. [CrossRef]

6. Odolinski, R.; Teunissen, P.J.G. An Assessment of Smartphone and Low-cost Multi-GNSS Single-frequency RTK Positioning for Low, Medium and High Ionospheric Disturbance Periods. J. Geod. 2019, 93, 701-722. [CrossRef]

7. Saeedi, S.; Moussa, A.; El-Sheimy, N. Context-aware Personal Navigation Using Embedded Sensor Fusion in Smartphones. Sensors 2014, 14, 5742-5767. [CrossRef]

8. Wang, D.; Park, S.; Fesenmaier, D.R. The Role of Smartphones in Mediating the Touristic Experience. J. Travel Res. 2011, 51, 371-387. [CrossRef]

9. Chen, B.; Gao, C.; Liu, Y.; Sun, P. Real-time Precise Point Positioning with a Xiaomi MI 8 Android Smartphone. Sensors 2019, 19, 2835. [CrossRef] [PubMed]

10. Paziewski, J.; Sieradzki, R.; Baryla, R. Signal Characterization and Assessment of Code GNSS Positioning with Low-power Consumption Smartphones. GPS Solut. 2019, 23, 98. [CrossRef]

11. Specht, M.; Specht, C.; Lasota, H.; Cywiński, P. Assessment of the Steering Precision of a Hydrographic Unmanned Surface Vessel (USV) along Sounding Profiles Using a Low-cost Multi-Global Navigation Satellite System (GNSS) Receiver Supported Autopilot. Sensors 2019, 19, 3939. [CrossRef]

12. Wang, L.; Li, Z.; Zhao, J.; Zhou, K.; Wang, Z.; Yuan, H. Smart Device-supported BDS/GNSS Real-time Kinematic Positioning for Sub-meter-level Accuracy in Urban Location-based Services. Sensors 2016, 16, 2201. [CrossRef] [PubMed]

13. Jiao, G.; Song, S.; Ge, Y.; Su, K.; Liu, Y. Assessment of BeiDou-3 and Multi-GNSS Precise Point Positioning Performance. Sensors 2019, 19, 2496. [CrossRef]

14. Lohan, E.S.; Borre, K. Accuracy Limits in Multi-GNSS. IEEE Trans. Aerosp. Electron. Syst. 2017, 52, 2477-2494. [CrossRef]

15. Wu, M.; Liu, W.; Wang, W.; Zhang, X. Differential Inter-system Biases Estimation and Initial Assessment of Instantaneous Tightly Combined RTK with BDS-3, GPS, and Galileo. Remote Sens. 2019, 11, 1430. [CrossRef]

16. Zhang, Q.; Yang, W.; Zhang, S.; Yao, L. Performance Evaluation of QZSS Augmenting GPS and BDS Single-frequency Single-epoch Positioning with Actual Data in Asia-Pacific Region. ISPRS Int. J. Geo-Inf. 2018, 7, 186. [CrossRef]

17. Zhang, R.; Tu, R.; Liu, J.; Hong, J.; Fan, L.; Zhang, P.; Lu, X. Impact of BDS-3 Experimental Satellites to BDS-2: Service Area, Precise Products, Precise Positioning. Adv. Space Res. 2018, 62, 829-844. [CrossRef]

18. Ziquan, H.; Xiufeng, H.; Liu, Z.; Sang, W. Analysis of the DOP Values and Availability of Combined GPS/GLONASS/GALILEO Navigation System. GNSS World China 2012, 37, 32-37.

19. Langley, R.B. Dilution of Precision. GPS World 1999, 10(5), 52-59.

20. Specht, C.; Mania, M.; Skóra, M.; Specht, M. Accuracy of the GPS Positioning System in the Context of Increasing the Number of Satellites in the Constellation. Pol. Marit. Res. 2015, 22, 9-14. [CrossRef] 
21. Teunissen, P.J.G.; Odijk, D. Ambiguity Dilution of Precision: Definition, Properties and Application. In Proceedings of the 10th International Technical Meeting of the Satellite Division of The Institute of Navigation (ION GPS 1997), Kansas City, MO, USA, 16-19 September 1997.

22. Ito, M.; Shoji, K. GPS Receiver Capable of Calculating Accurate 2DRMS. U.S. Patent 6,407,701 B2, 28 June 2002.

23. Su, M.; Su, X.; Zhao, Q.; Liu, J. BeiDou Augmented Navigation from Low Earth Orbit Satellites. Sensors 2019, 19, 198. [CrossRef]

24. Tahsin, M.; Sultana, S.; Reza, T.; Hossam-E-Haider, M. Analysis of DOP and its Preciseness in GNSS Position Estimation. In Proceedings of the 2015 International Conference on Electrical Engineering and Information Communication Technology (ICEEICT 2015), Dhaka, Bangladesh, 21-23 May 2015.

25. Tongyu, Z.; Aihua, X.; Rui, S. Evaluation on User Range Error and Global Positioning Accuracy for GPS/BDS Navigation System. In Proceedings of the 2014 IEEE Chinese Guidance, Navigation and Control Conference (IEEE CGNCC2014), Yantai, China, 8-10 August 2014.

26. Ge, Y.; Dai, P.; Qin, W.; Yang, X.; Zhou, F.; Wang, S.; Zhao, X. Performance of Multi-GNSS Precise Point Positioning Time and Frequency Transfer with Clock Modeling. Remote Sens. 2019, 11, 347. [CrossRef]

27. Li, X.; Lv, H.; Ma, F.; Li, X.; Liu, J.; Jiang, Z. GNSS RTK Positioning Augmented with Large LEO Constellation. Remote Sens. 2019, 11, 228. [CrossRef]

28. Li, X.; Zhang, X.; Ren, X.; Fritsche, M.; Wickert, J.; Schuh, H. Precise Positioning with Current Multi-constellation Global Navigation Satellite Systems: GPS, GLONASS, Galileo and BeiDou. Sci. Rep. 2015, 5, 8328. [CrossRef] [PubMed]

29. Maciuk, K. GPS-only, GLONASS-only and Combined GPS+GLONASS Absolute Positioning under Different Sky View Conditions. Teh. Vjesn. 2018, 25, 933-939.

30. Duerr, T.E. Effect of Terrain Masking on GPS Position Dilution of Precision. Navig. J. Inst. Navig. 1992, 39, 317-323. [CrossRef]

31. Li, N.; Gao, Y.; Wang, Y.; Liu, Z.; Guan, L.; Liu, X. A Low-cost Underground Garage Navigation Switching Algorithm Based on Kalman Filtering. Sensors 2019, 19, 1861. [CrossRef] [PubMed]

32. Robustelli, U.; Pugliano, G. Galileo Single Point Positioning Assessment Including FOC Satellites in Eccentric Orbits. Remote Sens. 2019, 11, 1555. [CrossRef]

33. El-naggar, A.M. DOP Prediction over Egypt from SP3 File for Long-term. Alex. Eng. J. 2012, 51, 221-228. [CrossRef]

34. Mostafa, M.; Atia, K.; Khalil, R.; El-Gharbawi, T. Proposed Methodology for GPS Mission Planning. Alex. Eng. J. 2010, 49, 297-309.

35. Specht, C.; Skóra, M. Planning GPS Measurements of a Linear Object for a Specified Time Interval. Annu. Navig. 2017, 24, 1-13. [CrossRef]

36. Gandolfi, S.; La Via, L. SKYPLOT_DEM: A Tool for GNSS Planning and Simulations. Appl. Geomat. 2011, 3, 35-48. [CrossRef]

37. EUSPA. GeoPAL GNSS-based Planning System for Agricultural Logistics. Available online: https://www.euspa.europa.eu/gnssbased-planning-system-agricultural-logistics (accessed on 19 November 2021).

38. Grewal, M.S.; Weill, L.R.; Andrews, A.P. Global Positioning Systems, Inertial Navigation, and Integration; John Wiley \& Sons: Hoboken, NJ, USA, 2007.

39. Council of Ministers of the Republic of Poland. Act of 17 May 1989 Geodetic and Cartographic Law. Available online: https:/ / www.fig.net/resources/proceedings / fig_proceedings/fig2014/ppt/ts03b /TS03B_sato_7351_ppt.pdf (accessed on 19 November 2021). (In Polish)

40. Federici, A.; Giacomelli, D.; Sguerso, D.; Vitti, A.; Zatelli, P. A Web Processing Service for GNSS Realistic Planning. Appl. Geomat. 2013, 5, 45-57. [CrossRef]

41. Karimi, H.A.; Asavasuthirakul, D. A Novel Optimal Routing for Navigation Systems/Services Based on Global Navigation Satellite System Quality of Service. J. Intell. Transp. Syst. 2014, 18, 3860. [CrossRef]

42. Roongpiboonsopit, D.; Karimi, H.A. Integrated Global Navigation Satellite System (iGNSS) QoS Prediction. Photogramm. Eng. Remote Sens. 2012, 78, 139-149. [CrossRef]

43. Taylor, G.; Li, J.; Kidner, D.; Brunsdon, C.; Ware, M. Modelling and Prediction of GPS Availability with Digital Photogrammetry and LiDAR. Int. J. Geogr. Inf. Sci. 2007, 21, 1-20. [CrossRef]

44. Ragothaman, S.S. Path Planning for Autonomous Ground Vehicles Using GNSS and Cellular LTE Signal Reliability Maps and GIS 3-D Maps. Master's Thesis, University of California, Oakland, CA, USA, 2018.

45. Nowak, A. The Proposal to "Snapshot" RAIM Method for GNSS Vessel Receivers Working in Poor Space Segment Geometry. Pol. Marit. Res. 2015, 22, 3-8. [CrossRef]

46. Soloviev, A.; van Graas, F. Use of Deeply Integrated GPS/INS Architecture and Laser Scanners for the Identification of Multipath Reflections in Urban Environments. IEEE J. Sel. Top. Signal Process. 2009, 3, 786-797. [CrossRef]

47. Specht, M.; Specht, C.; Dąbrowski, P.; Czaplewski, K.; Smolarek, L.; Lewicka, O. Road Tests of the Positioning Accuracy of INS/GNSS Systems Based on MEMS Technology for Navigating Railway Vehicles. Energies 2020, 13, 4463. [CrossRef]

48. Jin, C.; Cai, B.; Wang, J.; Kealy, A. DTM-aided Adaptive EPF Navigation Application in Railways. Sensors 2018, $18,3860$. [CrossRef] [PubMed]

49. Hasan, M.; Rouf, R.R.; Islam, S. Investigation of Most Ideal GNSS Framework (GPS, GLONASS and GALILEO) for Asia Pacific Region (Bangladesh). Int. J. Appl. Inf. Syst. 2017, 12, 33-37. [CrossRef]

50. Kaya, F.A.; Saritas, M.A. A Computer Simulation of Dilution of Precision in the Global Positioning System Using Matlab. In Proceedings of the 4th International Conference on Electrical and Electronic Engineering (ELECO 2005), Bursa, Turkey, 7-11 December 2005. 
51. Protaziuk, E. Geometric Aspects of Ground Augmentation of Satellite Networks for the Needs of Deformation Monitoring. Artif. Satell. 2016, 51, 75-88. [CrossRef]

52. Specht, C.; Szot, T.; Dabrowski, P.; Specht, M. Testing GNSS Receiver Accuracy in Samsung Galaxy Series Mobile Phones at a Sports Stadium. Meas. Sci. Technol. 2020, 31, 064006. [CrossRef] 